\title{
Internacionalização acadêmica e/ou inclusão do estudante estrangeiro em Portugal: diversidade e diferença em questão
}

\author{
Academical internationalization and/or the inclusion of foreign student in portugal: \\ diversity and difference in question
}

Cláudia Madruga Cunha*

\section{Resumo}

\begin{abstract}
O estudo aborda o impacto da internacionalização e sua relação com a qualidade da educação superior. Analisa o tema a partir de uma investigação que teve como cenário a Universidade do Porto, em Portugal, incluindo gestores, pesquisadores e estudantes brasileiros. Para análise dos dados, toma como referência pressupostos do multiculturalismo ligado às teorias de Veiga-Neto, Stoer e Cortesão. Assume três conceitos, vindos dessas teorias, como pano de fundo para propor as dimensões de análise: inclusão, diversidade e diferença. Os resultados indicam a complexidade do tema e a importância de sua exploração. No caso das IES portuguesas, expressam a condição particular de um compromisso com a internacionalização solidária com as antigas colônias, ao mesmo tempo que o fenômeno contribui com a sustentabilidade das universidades portuguesas e para consolidação de seu prestígio. Em relação aos estudantes, a experiência contribui para o sentimento de pertencimento a um lugar temporário e fluído na sala de aula, onde o estudante estrangeiro constrói novos valores referentes à educação superior. As análises estimularam inferências no campo cultural, acadêmico e político.
\end{abstract}

Palavras-chave: Educação superior. Internacionalização. Multiculturalismo.

\section{Abstract}

The study approaches the impact of internationalization and its relation to quality of high education. It analyses the theme from an investigation hold in Porto University, in Portugal, including managers, researchers and Brazilian students. To analyze data uses as reference multiculturalism presupposes related to theories of Veiga-Neto, Stoer and Cortesão. It assumes three concepts from these theories as background to propose analysis dimensions: inclusion, diversity and difference. Results indicate theme complexity and importance of its exploration. In case of Portuguese universities it express a particular condition of an engagement with solidary internationalization with old colonies, at same time the phenomenon contributes to universities sustainability and to consolidate their prestige. In relation to the students, experience contributed to sense of belonging to a temporary and fluid place in classroom where foreign student builds new values referred to superior education. Analyzes stimulated inferences in cultural, academic and political field.

Keywords: High education. Internationalization. Multiculturalism.

Recebido em: 03/09/2016 - Aprovado em: 20/12/2016

http://dx.doi.org/10.5335/rep.v24i1.6996

Doutora em Educação pela Universidade Federal do Rio Grande do Sul, com pós-doutorado na UP-Portugal. Atua no Setor de Educação Profissional e Tecnológica SEPT e no PPGE/MP - Teoria e Prática de Ensino da UFPR. E-mail: cmadrugacunha@gmail.com 
Este artigo é parte de investigação realizada durante período de pós-doutoramento na Universidade do Porto, em Portugal, sobre o processo de internacionalização da educação superior. Trago, nesse recorte, alguns resultados sobre a condição de estudante estrangeiro, como esse sujeito se percebe nesse período de aprendizagem, no qual se desloca de sua cultura, seus hábitos, sua família, seus afetos para frequentar a universidade em outro território/nação.

Sensibilizada por estudar autores cujas teorias abordam contexto de mudanças provocadas pelo pós-estruturalismo e descolonização na Europa, não utilizados de forma direta aqui, tive um olhar referenciado ao estudante estrangeiro como objeto de estudo no Curso de Licenciatura em Ciências da Educação. Preferi demarcar o território conceitual dessa análise, utilizando a produção de conhecimento local e próximos. Tomei, por ponto de partida, as produções acadêmicas, as teses e as dissertações nas quais aparecessem problematizações teóricas sobre inclusão, diversidade e diferença.

Escolho esses conceitos por entender que povoam as escritas em busca de uma política da diferença. Esses foram usados como descritores co-ligados às perspectivas sociocultural e sociopolítica, na ideia de relacioná-los ao processo de globalização. Esse processo, geralmente reconhecido como produto das relações sociais que ligam localidades distantes, promove influencias nos contextos locais e nacionais (SANTOS, 2002). Tendo a Universidade do Porto como cenário, quis fazer inferências para outras instituições acadêmicas europeias.

A crescente interdependência mundial, revelada pela transnacionalização dos sistemas de produção e crescente constituição de organizações supranacionais de âmbito regional ou global, tem favorecido o desenvolvimento dos meios de comunicação e informação, assim como os deslocamentos maciços de pessoas, turistas, emigrantes ou refugiados. Tal cenário, onde indivíduos, grupos e comunidades se deslocam de modo temporário ou definitivo de seus países, tem impactado as instituições escolarizadas de todos os níveis.

As reflexões sugerem que há uma educação em nome do global que vem se diluindo, permitindo o escoamento de suas fronteiras identitárias, tornando seus blocos de verdades e seu conjunto de valores mais fluídos e menos definidos, como diz Bauman (1999). Nessa tendência, cada vez mais se desloca o eixo entre o Estado e a educação, no acréscimo das possibilidades da internacionalização acrescem saberes que vão na direção da consequente criação de interstícios.

Esse espaço do entre, produzido pela mediação entre governos e instituições, aponta para uma educação que propõe relações mais ou menos permanentes e temporárias, nas quais estudantes de diferentes representações de Estado, portanto, de outras relações saber/poder, dispõem de condições de aprender que se abrem a trocas. 
A questão do pertencimento cultural como um processo de construção singular entre indivíduo e meio, pode ser abalada nesse contato com outro contexto educativo cuja estrutura sustenta perfis profissional e de profissionalização dispostos em diferentes realidades econômicas. Provinda de acordos internacionais, a internacionalização da educação superior estimula práticas do acolhimento, social e cultural, fazendo desse nível de ensino superior um espaço de interstício que oculta interesses econômicos. Favorece para que o estatuto de estudante estrangeiro, o sujeito em mobilidade acadêmica, venha a contribuir com as permutas entre culturas e nações, incluindo seus diferentes modos de ensinar e aprender (CUNHA, 2011).

\section{Democratização e internacionalização}

Pesquisar a condição do estudante estrangeiro na Universidade do Porto forçou uma reflexão acerca do processo de democratização, processo que antecede o de internacionalização no continente europeu e nas américas. A democratização favoreceu a abertura das fronteiras entre os Estados e, internamente, gerou processos de inclusão. No Brasil, especialmente, o conceito de inclusão passou a fazer parte da pauta acadêmica após a constituição de 1988.

Esse conceito ganhou força na década seguinte, na qual foram ampliados os direitos à educação da população em geral, favorecendo os estudos sobre inclusão. Essa perspectiva se abasteceu dos estudos culturais europeus, vindos do contexto da sociologia da educação e de Paulo Freire, no Brasil, em diálogo com as pedagogias críticas e as filosofias da alteridade.

A democratização, em Portugal, ocorreu na década anterior, com a constituição de 1974. "O país fez a experiência de revolução política, seguida de uma breve revolução social” (BARRETO, 2003, p. 29). Do mesmo modo, a implementação de ações de democratização e de inclusão foi ocorrendo paulatinamente. No início dos anos setenta, havia em Portugal uma elevada taxa de migração, pessoas que saiam do país em busca de oportunidades de trabalho.

Quarenta anos depois o cenário se inverteu. Como disse Barreto, "A partir dos anos setenta e mais vigorosamente durante os anos oitenta e claramente nos noventa, a migração foi cessando sendo substituída pela emigração. Brasileiros e africanos (sobretudo estes de dos países de língua portuguesa) começaram a se instalar em Portugal" (2003, p. 69).

Precedendo a internacionalização, a democratização produziu um aparelhamento sociopolítico que oportunizou a presença de estrangeiros em Portugal, os retornados das colônias. Esse período de revolução sociopolítica forjou transformações culturais e econômicas. Segundo Cortesão, Dale e Magalhães 
[...] representou não só um conjunto de propostas, movimentos e eventos muito interessantes em si mesmo, mas também constituiu um exemplo de um caso muito particular de mudança nas relações entre Estado, sociedade e, consequentemente, nas políticas educativas. Os mandatos políticos dirigidos e assumidos pelo sistema educativo e a procura social da educação formal, assim como a educação informal e não-formal, mudaram, de fato, radicalmente (CORTESÃO; DALE; MAGALHES, 2014, p. 11).

Parecia haver um processo de produção de conhecimento e de construção de valores em curso, que deu origem as condições de ingresso e de permanência dos muitos estudantes que encontrava em terras portuguesas. Há uma hospitalidade portuguesa em relação a esse "irmão" de mesma cultura. Os fatos históricos vividos nas últimas décadas favoreceram a mestiçagem e a miscigenação e trouxeram a aceitação da pluralidade cultural, étnica e religiosa. Parafraseando Barreto (2003), alguns grupos perderam, renovaram ou alteraram suas referências e valores em contato com outras culturas. Cortesão (2000) deixa entender que foi um tempo em que se mostrou necessário um processo em que todos aprendessem a ser livres.

Em 2015, vinda do Brasil em para realizar estágio de pós-doutoramento em Portugal para estudar a internacionalização na Universidade do Porto, desde a chegada nessa instituição, me detive em observar os inúmeros estudantes em circulação vindos de muitos lugares. Procurei ser uma observadora dos seus movimentos, trajetos e modos de conviver, viver nesse ambiente acadêmico. Conclui que não apenas queria entender a internacionalização pela perspectiva da instituição como queria saber como os estudantes se percebem aprendendo, pertencendo e vivendo esse processo.

Fonseca e Encarnação ponderam que a expansão do ensino superior em Portugal, na última década, incluindo a mobilidade estudantil, trouxe resultados pouco positivos ao processo de alargamento desse nível de ensino.

À semelhança de outros países, o processo de massificação levou à diversificação e estratificação e a dispersão territorial não contribuiu para um maior equilíbrio entre a oferta e a procura, não se podendo afirmar inequivocamente, que se tenha assistido a uma democratização do sistema [...] em grande medida, relacionado com o anterior, que o alargamento do acesso tem encontrado um conjunto de barreiras, não só de caráter econômico, social e cultural mas também, territoriais que têm levado a uma reestruturação do sistema de ensino superior, com um aumento de diversificação e estratificação que tendencialmente reforçam a polarização de algumas localizações e instituições, num processo que poderíamos classificar de recomposição de um estrato elitista (FONSECA; ENCARNAÇÃO, 2012, p. 11).

A democratização em Portugal, como processo de inclusão está, ainda, em busca de êxito, especialmente considerando o contingente migratório. Assim como no Brasil, as avaliações externas tem trazido diagnósticos interessantes sobre a discussão de gênero, raça e etnia. $\mathrm{E}$, assim, tem mantido a agenda da democratização aberta. Estudos e pesquisas demonstram que há muito que avançar sobre 
diferentes aspectos na busca de equiparação social e na busca de intervenções que a contemple.

Outro estudo, que compara Brasil e Portugal, afirma que, neste último:

[...] a democratização do acesso em termos de equidade social suscita já sérias dúvidas e reservas e o problema ganha contornos mais evidentes quando se analisa a democratização do sucesso. Nesta altura, as taxas de abandono e de insucesso penalizam, sobretudo, os alunos provenientes dos estratos sociais mais desfavorecidos, mesmo não havendo estatísticas seguras para o demonstrar (ALMEIDA al., 2012, não paginado).

Os dados evidenciam que os incluídos, por suas diferenças socioculturais, evadem dos processos educativos em geral, quando sofrem avaliações negativas. São punidos por não se perceberem representados nos saberes escolares e acadêmicos.

De novo, a frequência a um curso de que não se gosta e a necessidade de conciliar os estudos com alguma forma de trabalho, mesmo que temporário (quando, por exemplo em Portugal, os horários de funcionamento das aulas são essencialmente diurnos) são fatores explicativos de uma taxa considerável de insucesso e de abandono, sobretudo junto dos alunos pertencentes aos grupos sociais mais desfavorecidos (ALMEIDA al., 2012, não paginado).

Cabe, então, refletir sobre os incluídos por meio de programas de internacionalização. Sendo ingressantes no ensino superior por políticas de cotas, como se sentem nessa condição? Não estarão a viver um processo análogo?

Estudos anteriores sobre a internacionalização do ensino superior revelam que:

[...] a diferenciação de classe continua sendo claramente reproduzida nos processos de acesso e conhecimento no âmbito das universidades públicas e das suas instituições financiadoras de pesquisa. No campo da produção de ciência e tecnologia, por exemplo, na dinâmica da produção do conhecimento, dificilmente pessoas provenientes de Instituições de Ensino Superior, consideradas periféricas ou das populações pobres terão acesso a programas financiados com recursos públicos, destinados a formar pessoas altamente qualificadas nas competências e habilidades necessárias para a produção de novos conhecimentos do atual modelo de desenvolvimento nacional e internacional. Este é o caso do programa Ciência sem Fronteiras, auspiciado pelo Ministério da Educação (MEC), em conjunto com o Ministério da Ciência e Tecnologia (MCT) (PRESTES; JEZINE; SCOCUGLIA, 2012, p. 207).

Pensando que a democratização nos seus muitos modos de incluir pode ser também excludente é possível extrair que, sem a alteração das bases institucionais que a implementou nas últimas décadas, o processo pode reproduzir a tensão dicotômica, apontada por Veiga-Neto e Lopes (2011). Os incluídos nas instituições estrangeiras são novos instituídos, os ex-colonizados com novos direitos, os estudantes estrangeiros e sua presença em aula conquistam um lugar de não-lugar; são a ocupação de um lugar de fora (de identidade e de individuação vindas de outro 
lugar/origem), onde o incluído ocupa um lugar daquele que substitui temporariamente.

Veiga-Neto e Corcini ressaltam que:

[...] não se trata de pensarmos a inclusão como algo da direita sobre a esquerda, dos dominantes sobre os dominados, dos normais sobre os anormais, nem mesmo como uma conquista de esquerda ou das minorias negativamente discriminadas ao longo da história. Tampouco se trata de reduzir a compreensão da inclusão - e dos sujeitos envolvidos nos processos de inclusão - nos limites das ações de Estado. Os sujeitos e a inclusão são, também, produtos das inúmeras técnicas de governamento, tanto sobre a população quanto de uns sobre os outros (2011, p. 125-6).

Não se está pondo em discussão a validade das políticas de internacionalização. Já se trata de um processo instituído e em expansão. Entretanto, essa problematização estimula a ouvir os estudantes estrangeiros para compreender como eles têm interagido com outros estudantes de mesma condição no país que os abriga.

Este lugar de fora, esse não-lugar, essa distância do país de origem, da cidade, da casa, do círculo familiar, dos amigos, dos círculos de estudo, de trabalho e das rotinas traz desafios que, certamente, envolvem novos modos de estudar e aprender. Ao mesmo tempo invisibiliza sua condição anterior, força-o a aprender de fora dos excessos de si, de fora muitas vezes do que resguarda a afirmação da sua própria cultura.

Foi possível observar a Universidade do Porto põe em prática uma política de acolhimento e estímulo. Entretanto, “[...] é preciso examinar tudo isso como resultado de construções sociais que, justamente por serem sociais, são históricas, contingentes, culturais, políticas e, portanto, modificáveis" (VEIGA-NETO; CORCINI, 2011, p. 129). Quando se visualiza a internacionalização na homepage institucional, impõe um convite, uma inclusão por via segura, a um novo modelo em ensino superior, inclusão que se faz sob um fundo econômico.

\section{Construção da trajetória da pesquisa}

Utilizei o Banco da Dados da Biblioteca da Faculdade de Psicologia e Ciências da Educação/FPCEUP na ideia de que encontraria pesquisas sobre o tema da inclusão cultural. Os resultados ${ }^{1}$ encontrados me desapontaram. Descontente com esses dados, passei a procurar dissertações e teses que tratassem da diversidade e da diferença.

O resultado dessa primeira investida é que a presença de estrangeiro está banalizada em Portugal. Há trinta anos, receber estrangeiros ou pessoas de fora de seus país, impactou os portugueses, sua cultura, estrutura social, econômica e 
política. Mas hoje o país está moldado ao acolhimento desse outro, uma vez que a globalização econômica não trouxe apenas o estudante estrangeiro, trouxe também o turista e a mão de obra desqualificada.

Quis entender como os portugueses problematizavam a presença estrangeira nos processos de educação, mas a produção discente sobre esse tema não é significativa, mas proporcionou o encontro com a produção docente. Sthepen Stoer, Luiza Cortesão, entre outros pesquisadores têm contribuições fundamentais para a inclusão cultural em Portugal.

Ambos tencionaram o processo de democratização e seus frutos, a inclusão dos retornados e o impacto da massificação da educação em todos os níveis em Portugal, foram debatidos junto a temas que tencionaram a relação entre "educação e regulação" e entre "educação e emancipação". Esses opostos e seus enfrentamentos passaram a se constituir, no contexto globalização da economia, em proposta de transnacionalização da própria educação. Para Stöer:

[...] a transnacionalização constitui uma globalização de baixa intensidade do modo de regulação dominante nas políticas educativas, exemplificado pelos efeitos indiretos que sobre estas exercem os grandes projetos estatísticos internacionais, por um lado, e pelas relações entre as organizações internacionais e a formulação das políticas educativas nacionais, por outro (STOER, 2002, p. 37).

É provável que esse processo de internacionalização, de algum modo, venha enfraquecendo o debate sobre a coexistências das culturas e o convívio de suas diferenças em espaços de intersecção. Foi possível perceber que em Portugal as iniciativas relativas à democratização enfrentam desafios vindos do alargamento de direitos a grupos excluídos e/ou invisibilizados (CORTESÃO, 2011).

No território português as equiparações sociais vinham sendo mais efetivas nas últimas décadas, antes da última crise econômica europeia. Na educação, em todos os níveis, houve movimentos do Estado na busca de garantir um horizonte de inclusão dos grupos reconhecidos como excluídos. Esses movimentos, mesmo que hoje estejam mais enfraquecidos, não se ausentaram de reivindicar uma gestão mais equitativa do Estado. Ligado à globalização da economia, o processo de democratização permite como consequência que se aborde:

[...] o novo papel (regulador e avaliador) do Estado através do estudo da criação em Portugal de uma rede nacional de Escolas Profissionais que, por sua vez, é indissociável da emergência de processos de construção de um referencial global europeu e da interpenetração das políticas educativas públicas nacionais e comunitárias. Este papel é também estudado através da abordagem da evolução do sistema de ensino superior, onde se encontra a atribuição de uma importância crescente à auto-regulação institucional e à empresarialização da educação (STOER, 2002, p. 37). 
Para além de um novo papel do Estado, a democratização trouxe para o ensino superior, novos modos de aprender e ensinar, a ordem desse novo sistema é intervir. Stöer e Magalhães, analisando o legado de Cortesão para esse período, dizem que a "preocupação com as questões da educação inter-multicultural são a continuação do processo crítico de politização da educação, agora por outros meios. O primeiro aspecto dessa politização da educação é o da assunção da 'diferença' como conceito central" (2004, p. 16-17).

Subjacente ao processo de internacionalização, processo que propicia que se encontre hoje na universidade do Porto estudantes de vários países da África e da América do Sul, na latência desse processo, reside um outro, o de democratização, que em Portugal teve características bem específicas quando do retorno de um contingente enorme de pessoas (600 000) vindas das ex-colônias (BARRETO, 2003).

Cortesão (2000) elaborou um conjunto de conceitos para problematizar as questões dos imigrantes e desses novos atores de direito, incluídos nas últimas décadas no sistema educativo português. São eles: "o daltonismo cultural", "o dispositivo de diferenciação pedagógica", "a interface da gestão educativa inter-cultural", "o bilinguismo cultural" entre outros conceitos. Esse conjunto conceitual revela investimentos em inclusão de sujeitos, de classe, de etnia e de gênero; que, por via do fenômeno da massificação da própria educação, acabou por aparelhar a instituição pesquisada para o processo de integração de diferentes sujeitos e culturas no seu processo educativo (STÖER; MAGALHAES, 2004).

\section{Conquista dos sujeitos da pesquisa}

Paralelamente ao levantamento das produções acadêmicas, procurei compreender como essa instituição acolhe, abriga e promove, as condições de permanência temporária dos estudantes estrangeiros, em três ambientes: a Universidade do Porto; a Faculdade de Psicologia e Ciências da Educação (FPCEUP) e o Curso de Licenciatura em Ciências da Educação (LCE).

Me detive em saber como ocorre o ingresso do estudante em mobilidade, quais caminhos ele percorre para chegar à sala de aula. $\mathrm{O}$ documento intitulado protocolo de recepção do estudante estrangeiro é emitido pela Reitoria, em concomitância, com o Serviço de Relações Internacionais e Mobilidade ${ }^{2}$ do Setor no qual se localiza o Curso que o hospeda. Para entender esse processo foram realizadas entrevistadas com a Vice-Reitora da Universidade, com as servidoras técnicas responsáveis pela internacionalização na Reitoria e no FPCEUP. Também ouvimos a professora que coordena o Curso de Licenciatura. 
A oportunidade de ter ministrado uma disciplina optativa no Curso de Ciências da Educação, intitulada "Filosofia e Ética Profissional" foi importante, pois favoreceu um olhar de dentro desse de inclusão; convivi com estudantes estrangeiros de língua lusófona e outros que só se comunicavam em inglês; dois deles de origem tcheca. Essa condição me colocou em contato direto com um contexto de aula em que a presença dos estrangeiros era significativa.

Questionei, então, sob outro ângulo sobre a importância desse deslocamento para estudos de graduação e como a internacionalização poderia impactar a formação desses jovens estudantes. Essa convivência derivou em um procedimento de observação de cunho etnográfico com registros em caderno de campo após as aulas.

Também foi possível aprofundar dados com a ajuda de dois estudantes, um de mestrado e outra de graduação, que se apresentaram voluntariamente para ampliar a experiência da pesquisa. Ambos se tornaram parceiros no estudo e os menciono por reconhecimento: o prof. Simão Sumbane estudante de mestrado na Universidade do Porto vindo da colaboração internacional com a Universidade Maxixe, em Moçambique e a acadêmica Maria Carolina Branco Costa, estudante de pedagogia da Universidade Estadual de São Paulo/Unesp, que estava em mobilidade no curso Licenciatura em Ciências de Educação. Os dois participaram da formulação do questionário para os estudantes em mobilidade acadêmica, contribuindo para sua validação. Ajudaram, também, a localizar e convidar outros estudantes, colegas, para colaborar com a pesquisa.

O Gabinete de Mobilidade informou que havia noventa estudantes estrangeiros, matriculados no curso de Licenciatura em Ciências da Educação (LCE), sendo que desses, trinta eram brasileiros. Com base nesse dado, após a discussão e a análise das questões, os questionários foram aplicados ao modo de um grupo focal, em quatro encontros com grupos de dois e três participantes. Tivemos por respondentes dez dos trinta estudantes matriculados em 2015 no LCE, apenas três deles foram meus alunos.

Os dados obtidos foram submetidos à análise do discurso e resultaram organizados em três dimensões: 1) políticas e práticas de internacionalização na Universidade do Porto; 2) políticas e práticas de internacionalização no LCE; 3) percepções dos estudantes estrangeiros no LCE enfocando sobre os modos de serem incluídos nas práticas de sala de aula.

A procura de significados nos discursos foram importantes dispositivos de fundamentação do estudo. Após a leitura recorrente das entrevistas foi feita uma primeira classificação dos núcleos de respostas que, afinados progressivamente, deram suporte para a definição das dimensões de análise. 


\section{Processo e roteiro da pesquisa}

Olhando para todo esse cenário parece ambíguo que por um lado a política institucional invista no estudante internacional e, por outro, não se encontre estudos sobre a condição de estudante estrangeiro, em um Setor que problematiza a educação. A pesquisa foi desdobrada em três roteiros, com a intenção de entender as mudanças que o cenário da internacionalização vem produzindo nos espaços de ensinar e aprender na Universidade do Porto.

Tal organização oportunizou perceber ou compreender:

- O primeiro roteiro investigou a "política de inclusão" do estudante estrangeiro, explorou documentos e protocolo de recepção internos e o site institucional, conjugados com entrevistas com a Vice-Reitoria, a Coordenação de Curso e as Técnicas administrativas ligadas a ambas. Pude verificar que um conjunto de fatores institucionais se modificaram com essa política, e propuseram por meio dela a ampliação da estrutura física; o preparo dos profissionais para lidar com essa realidade; a reestruturação na hierarquia da gestão acadêmica e outros efeitos visíveis da estrutura universitária europeia, impactando o Curso de Licenciatura em Ciências de Educação, na Universidade Porto, após Processo de Bolonha. ${ }^{3}$ Ficou igualmente claro que esse cenário de reformulações trouxe ganhos e perdas ao perfil da Universidade.

- O segundo roteiro se dirigiu ao curso de Licenciatura em Ciências de Educação, ao Setor que hospeda esse curso e por ali as "produções e práticas da diversidade", exploradas no acervo do Banco de Dados da Biblioteca de FPCEUP. ${ }^{4}$ Ouvi, de três pesquisadores da FPCEUP, com reconhecidos estudos na área, que essa licenciatura tendo nascido no contexto de democratização portuguesa dos anos 80 do século $\mathrm{XX}$, foi paulatinamente atingida em sua estrutura pela adesão a Bolonha. No que diz respeito ao currículo e às práticas educacionais, os meios que estruturam esse curso, hoje, contam com menores recursos do governo, logo isso altera os fins para o quais se organiza (STOER, 2002). A presença de no mínimo $20 \%$ a $30 \%$ das turmas sendo compostas, por estudante de estrangeiro, causa impactos na identidade dessa formação e especificidade desse profissional da educação;

- O terceiro roteiro apontou para a presença em sala de aula do estudante estrangeiro; passei a ponderar que esse ocupa um lugar temporário que pode ser visto também como não-lugar, de fato, embora de direto, conquistado pelos novos valores impostos pela economia global (STOER, 2002). Nesse sentido, a presença de estudantes estrangeiros nas aulas desse nível de en- 
sino, que ocorre de forma parcial ou integral, no nível da graduação e no de pós-graduação, impacta as políticas institucionais e a prática pedagógica. Logo, é bem possível que o momento sociopolítico, que se caracteriza pela predominância da mercantilização, esteja agregando novas compreensões e expectativas para o Ensino superior.

Com esse último roteiro dirigido à sala de aula, tratei da dimensão "percepção da diferença", analisei os depoimentos de dez estudantes brasileiros matriculados no LCE. ${ }^{5}$ Resumindo os três roteiros associados a dimensões institucionais se agregaram aos conceitos de inclusão, diversidade e diferença. Demarquei entre os roteiros, as dimensões e os conceitos, um modo de analisar qualitativamente a condição do estudante estrangeiro no ensino superior.

No quadro a seguir, desenho o processo de planejamento do estudo, com vistas à sua melhor compreensão.

Quadro 1 - Organizador dos objetivos e ações da pesquisa

\begin{tabular}{|l|l|l|}
\hline $\begin{array}{l}\text { Roteiro 1. Política de inclusão } \\
\text { Objetivo: Caracterizar o proces- } \\
\text { so na Universidade do Porto } \\
\text { (Ação 2); }\end{array}$ & $\begin{array}{l}\text { Roteiro 2. Produções e Práticas } \\
\text { da diversidade } \\
\text { Objetivo: Caracterizar no contexto } \\
\text { da Licenciatura em Ciências da } \\
\text { Educação (Ação 1); }\end{array}$ & $\begin{array}{l}\text { Roteiro 3. Percepção da diferença } \\
\text { Objetivo: Caracterizar a percepção } \\
\text { de si (diferença) ou os efeitos da } \\
\text { presença do estudante estrangeiro } \\
\text { (Ação 3); }\end{array}$ \\
\hline $\begin{array}{l}\text { Materiais: } \\
\text { Protocolo Institucional }\end{array}$ & $\begin{array}{l}\text { Materiais: Produção docente e } \\
\text { professores da Licenciatura em } \\
\text { LCE }\end{array}$ & $\begin{array}{l}\text { Materiais: Protocolos de observação } \\
\text { e de práticas de sala de aula }\end{array}$ \\
\hline $\begin{array}{l}\text { Sujeitos da pesquisa: } \\
\text { Eécnicos e Gestores } \\
\text { cumtrevista e análise de do- }\end{array}$ & $\begin{array}{l}\text { Sujeitos da pesquisa: Docentes } \\
\text { pesquisadores do ClIE Pesquisa } \\
\text { banco de dados da biblioteca a) } \\
\text { Produção discente e produção } \\
\text { docente; b). Entrevistas a pesqui- } \\
\text { sadores do pesquisadores do CllE }\end{array}$ & $\begin{array}{l}\text { Sujeitos da pesquisa: Estudantes } \\
\text { aostrangeiros brasileiros Entrevista }\end{array}$ \\
\hline $\begin{array}{l}\text { Realização: } \\
\text { Junho, julho e agosto de 2015 }\end{array}$ & $\begin{array}{l}\text { Realização: a) abril, maio, junho focais } \\
\text { julho, 2015; b) outubro, novem- } \\
\text { bro, dezembro, janeiro e fevereiro } \\
\text { de 2016 }\end{array}$ & $\begin{array}{l}\text { Realização: Novembro e dezembro } \\
\text { de 2015 }\end{array}$ \\
\hline
\end{tabular}

Desdobrando o cenário em que a internacionalização ocorre, investiguei no âmbito institucional mais amplo, inspirada por Santos (2011), que a política institucional local faz certa tradução da política global. Entre entrevistas e visitas à Vice-Reitoria, percorri o protocolo ou a "política de inclusão" do estudante estrangeiro na UP. A seguir, dirigi a atenção ao Setor FPCEUP, ali procurei pelos temas de pesquisa, "produções e práticas da diversidade"6 cultural nos espaços da Licenciatura em Ciências da Educação (LCE); para então por fim, chegar aos estudantes. 
$\mathrm{Na}$ oportunidade de dar aulas como professora estrangeira, abriu-se um espaço de escuta. Percebi certo não-lugar do estudante estrangeiro ou indiferença a sua "diferença", na classe, uma vez que comunguei com esses a mesma condição temporária, embora desfrutando de um outro lugar na sala de aula convivi com a transnacionalização dos lugares da sala de aula com as múltiplas relações de poder que essa perfaz (STOER; CORTESÃO, 1999; STOER; ARAUJO, 2000; STOER; CORTESÃO; CORREIA, 2001; STOER, 2002). No lugar de professora estrangeira, que fala com quase todos a mesma língua, pude dispor de um lugar de acolhida de meninos e meninas que queriam falar do como percebiam sua experiência nesse ambiente. Logo, a construção dessa pesquisa e sua trajetória se fizeram em processo não linear.

O processo de pesquisa se desenvolveu no tempo programado e os dados foram analisados a partir da coleta. Dada a riqueza dos mesmos, fica a possibilidade de outras explorações e a condição de dar suporte a novos estudos.

\section{Dialogando com os achados: inclusão, diversidade e diferença no LCE}

O questionário aplicado ao estudantes estrangeiros foi organizado retomando os três lugares ou dimensões que subjazem ao roteiro: a política de inclusão da instituição; as práticas docentes em aula, voltadas ou não à diversidade cultural; a disposição à convivência e a aceitação da diferença do colega estrangeiro na aula. Como os brasileiros eram o maior número de estudantes estrangeiros foram tomados como sujeitos da pesquisa.

Dos sujeitos da pesquisa, cinco são mulheres e vem do Curso de Pedagogia, identificadas como P1, P2, P3, P4, P5; dois são estudantes de Educação Física, EF1, EF2; dois cursam História, H1, H2; e um Geografia, G1, todos de universidades públicas brasileiras. A maioria escolheu Portugal pela facilidade da língua, embora alguns sejam fluentes em inglês. Nove deles estavam em mobilidade acadêmica utilizando uma das modalidades de bolsa Erasmus.

Seguindo o roteiro tríplice: a Dimensão Um, que trata da política de inclusão, os estudantes são elogiosos da forma como foram recebidos na Universidade do Porto. Embora alguns salientem que há sempre um período de instalação difícil, a Instituição procura facilitar, oferecendo uma lista de possíveis futuras moradias, ajudando-os a localizá-las e contatá-las. A Reitoria proporciona festas de recepção, nas quais são festejadas as diferentes culturas. Informam que há um conjunto de espaços de interação disponibilizados para que o estudante se sinta acolhido.

Quanto à Dimensão Dois, em que o estudo abordou as produções e práticas da diversidade, as respostas foram múltiplas. Um dos meninos, G1, mencionou o 
desafio de estudar em um texto em inglês, o qual a professora pediu para que eu traduzisse para ela; mas foi bom. Pois a partir disto ela passou a gostar de mim. Todos revelaram alguma dificuldade com o português nativo, falado pelos professores. Uma das alunas de Pedagogia, P4, assim se expressou: percebo esforço nos professores de serem entendidos, falam mais devagar, demonstrando boa vontade com os estrangeiros. P4 também se percebeu deslocada nos primeiros dias de aula. Os estudantes portugueses fingem que querem ser receptivos mas não são totalmente...”. As demais estudantes do Curso de Pedagogia P1, P2, P3, afirmaram também sentir certo preconceito em aula, principalmente, no início do semestre. Entendem que os professores são bons mediadores em aula, se esforçam em reunir estudantes estrangeiros com estudantes portugueses, organizando eles mesmos os grupos de trabalho para estimular a interação. P4 recordou: "Lembrei de uma situação que aconteceu comigo no começo. Quando íamos dar nossa opinião, a sala inteira se virava para olhar para nós, para o intercambista, [...] sim, para verificar se temos bases teóricas, mas foi muito engraçado, eles olhavam e ficavam esperando a professora condenar minha fala".

Já na Dimensão Três, em torno da questão da percepção da diferença apareceu como um fenômeno recorrente a declaração de que os estrangeiros pouco convivem com os nativos, no espaço da aula ou fora dela. Ou pode-se entender que não há propriamente uma recepção à diferença. Alguns aspectos, entretanto chamaram atenção nos depoimentos dos interlocutores.

Disseram que, como a maioria dos alunos vêm de lugares quentes do Brasil (P3, P4, P5, EF1, G1, G2, H1), precisaram mudar o modo de vestir, adquirir roupas e valorizar as formas de seus colegas. Eles percebem os estudantes portugueses como sujeitos mais retraídos na aula, mais formais e menos participantes. Porém, afirmaram que também eles mudaram rotinas de estudo, de alimentação e de vida. Creem que em Portugal se alimentam de maneira menos saudável, pois a dieta local é mais calórica e menos rica em vegetais e frutas. Uma das respondentes chegou a sugerir que a cantina da Universidade ficasse mais atenta aos hábitos dos estrangeiros.

Todos mencionaram que a experiência de internacionalização mudou seu modo de ver muitas coisas, inclusive a si mesmos. Um dos estudantes de História declarou que viveu um "processo de declínio e superação [...] houve uma mudança comigo, acho o intercambio, além de outras coisas, proporciona isto, proporciona reflexão". Todos elogiavam a possibilidade de fazer novas amizades, de descobrir e conhecer novos lugares e mundos; dizem despertar para a possibilidade de que essas relações estabelecidas em situação temporária, sejam, também, um modo de vida afetiva e social diferente. Eles têm uma expectativa grande sobre o retorno ao 
Brasil. Preocupam-se, principalmente, com a validação dos estudos feitos em Portugal, pois nem todas as IES brasileiras têm processos avançados nesse sentido.

A análise do cenário da Universidade do Porto facilita ampliar alguns pontos de generalização entre as IES portuguesas e certamente condiciona a ampliação no contexto europeu. É visível que, em Portugal, há um sentimento próprio de responsabilização com as questões educacionais de suas ex-colônias que, no caso da África, tão recentemente se tornaram independentes.

Já com o Brasil, a facilidade do idioma e a melhor posição socioeconômica no contexto das nações de línguas luzas, vem estimulando a captação de estudantes como uma condição de sustentabilidade das próprias IES portuguesas. Mesmo não sendo o objeto específico deste estudo, a convivência no campo favoreceu compreender também o interesse em captar estudantes de outros países europeus, americanos e asiáticos, como reafirmação da qualidade da educação da Universidade do Porto.

\section{Considerações finais}

Chamo de conclusões temporárias as inferências atuais sobre a pesquisa realizada, por entender que o já produzido vai dialogar com o estudo mais amplo sobre o tema da internacionalização e seus efeitos nas aprendizagens acadêmicas e profissionalizantes. Assim, os entendimentos desenhados neste estudo refletem um cenário de mudança de valores na realidade acadêmica. Ponderar sobre a internacionalização a partir de Roteiros para dar conta de três dimensões possibilitou assumir certa equidade dos benefícios do conhecimento de como o saber pode ser transferível ao modo de uma equiparação, ainda que negociável entre os povos, como algo que se faça com maior ou menor justiça, em se tratando de bem comum.

Quanto à política de inclusão, foi possível observar que, na Universidade do Porto ela parece estar naturalizada na cultura local, suavizando seus impactos. Tal ocorrência pode ser resultado da vivencia dessa comunidade um longo processo de transformação cultural que começou com o "regresso de antigos colonizados", 1974 e 1975 (STOER; CORTESÃO, 1999; BARRETO, 2003; CORTESÃO, 2000). Desde esse tempo, instalou-se um movimento de inclusão social e econômica, que desenhou a democracia portuguesa. Esta, enquanto estrutura sociopolítica, levou cerca de dez anos para se consolidar, influenciando suas instituições.

Nesse contexto histórico, se disseminou a inclusão como postura de uma política nacional, o que refletiu na estrutura educacional e agregou novos valores de ordem social e cultural. O território português, ao lado da presença do estrangeiro, do colonizado regressado e do vizinho europeu, foi se reinventando. 
Trouxe consigo, também, um tipo de estudante estrangeiro de cidadania portuguesa. Foram tempos processuais de modernização que prepararam o terreno para as reflexões posteriores sobre a globalização. Tal processo, condicionado pela simultaneidade da crise e da consolidação da escolarização de massas, conduziu, simultaneamente, à desconstrução da escolarização como preservação e afirmação da identidade nacional.

Quanto às produções e práticas da diversidade foi possível observar que, tanto a produção docente como o currículo e as práticas pedagógicas mostram elos com uma conscientização que opera conceitos de uma educação inter-multicultural (STOER; CORTESÃO, 1999). Tal consenso mobiliza, na determinação estrutural do processo educativo, uma condição que envia ações de respeito ao diverso. Forjada nas necessidades que uma nova democracia criou, em outros tempos, indigências fundantes do que se mostra hoje como sociedade portuguesa.

O Curso de Licenciatura em Ciências da Educação ${ }^{7}$ nasceu, enquanto proposta de profissionalização, voltado para a mediação de questões que envolvem a relação da universidade com a escola, do governo com a sociedade e da escola com essa sociedade. Incluiu a importância da estrutura de produção e de socialização, entre outras mediações que tiveram a década de setenta como protagonista.

Para a construção do currículo deste Curso, a Instituição contou com profissionais da educação superior engajados politicamente, não apenas por uma perspectiva sociocultural, uma vez que esses defenderam uma política da percepção da diferença, para mediar os problemas advindos da explosão social dos anos 1970, mas incluindo as questões que traziam no seu bojo o tema das diversidades.

No contexto resgatado, em função da história da Licenciatura em Ciências de Educação, se percebe uma disposição para mediação que pode estar sendo alterada, quando inspirada por outros valores hoje presentes na educação superior.

Quanto à percepção da diferença, foi possível perceber o foco na aprendizagem dos estudantes, repensando as competências exigidas pelo mundo produtivo e globalizado. Incluiu a maior disposição, responsabilidade, autonomia e comprometimento dos discentes.

Essa aprendizagem autônoma, com as condições que a acompanham, provoca ambiguidades na cultura acadêmica, sendo possível apontar prós e contras. $\mathrm{O}$ efeito negativo refere-se à exigência de novas alternativas intermediárias no processo de ensinar e aprender, como ambientes de tutoria, cuja eficiência ainda está em questão. Entretanto, continua a exigir o acompanhamento e supervisão dos processos de formação dos estudantes que tendem a sobrecarregar o professor com novas atividades burocráticas. $\mathrm{O}$ efeito positivo se faz na possibilidade de construir um aprendizado mais dinâmico e autônomo, em que o estudante assume o prota- 
gonismo de sua própria aprendizagem ao encarar a necessidade de desenvolver habilidades de estudo e capacidades para o trabalho coletivo.

É provável que nesses distintos cenários, as disposições para a inclusão, diversidade e diferença assumam diferentes possibilidades e intensidades. Há, de forma constante, discursos em tensão e forças políticas que interagem nesses diferentes contextos.

E a Universidade do Porto, tal como as demais, não está isenta dessas características e contradições. Também há de se considerar as políticas e as tradições institucionais como intervenientes. Cada IES tem uma história, está sujeita a condições de suas culturas acadêmicas e tem pretensões próprias em relação ao futuro.

Embora a pesquisa da condição de estrangeiro não seja amplamente desenvolvida, a diferença sociocultural associada ao multiculturalismo na educação teve forte debate em Portugal e tem se mantido no Brasil. É certo que o contexto da internacionalização como um critério de alargamento da democratização da educação superior ainda está em processo e exigirá significativos investimentos de estudos e pesquisas. Mesmo reconhecendo benefícios e a impossibilidade de um afastamento da aldeia global, é preciso estar em estado de alerta, questionando as relações culturais de poder e os mecanismos de exclusão que os sistemas generalizadores impõem às populações historicamente alijadas dos bens econômicos e sociais.

Perante uma globalização predatória e competitiva, é possível se contrapor com outra, alicerçada na solidariedade, na qual a diferença soma em termos de capital cultural a diversidade de saberes e de experiências, não discrimina ou reduz em termos de capital econômico a presença do estudante estrangeiro a "inter-multiculturalismo massificado".

Nesse contexto a educação superior parece ser a única possibilidade com força e tradição para atuar nesse equilíbrio. São muitos os ganhos percebidos pelos estudantes estrangeiros, há um perceptível amadurecimento desse olhar forçado a se perceber no mundo. $\mathrm{O}$ que se pode questionar é se esse exercício de perceber-se no mundo não pode estar sendo mal conduzido e vir a se tornar um capital de exclusão pura, de excesso de individualismo na visibilização excessiva da cultura de alguns povos e na invisibilização da cultura de outros, pois, afinal, o daltonismo cultural nada mais é do que uma cromatopseudopsia da diferença. Estará a universidade atenta a essas questões? 


\section{Notas}

1 Fiz pesquisa nas biblioteca digitais de outras cinco (5) importantes instituições superiores portuguesas: Universidade do Minho, da Universidade de Lisboa, da Universidade de Coimbra, Universidade de Aveiro e os resultados foram muitos semelhantes, o tema da inclusão é majoritariamente ligado a Educação Especial.

2 O Serviço de Relações Internacionais e Mobilidade é a estrutura na FPCEUP responsável por apoiar e desenvolver as atividades que contribuam para a internacionalização da Faculdade, promovendo o envolvimento da mesma em programas nacionais e internacionais nos domínios da educação, da formação, da cooperação e da mobilidade de estudantes e staff.

3 O Processo de Bolonha, legislado em Portugal em 2006, através do Decreto- -Lei no 74/2006 (PORTUGAL, 2006).

4 Acesso pelo portal: <https://sigarra.up.pt/up/pt>.

5 Participaram em programas de mobilidade estudantil na Universidade do Porto 854 estudantes (mais 129 que no ano anterior), de 63 IES, de 7 países latino americanos - Argentina, Brasil, Chile, México, Uruguai, Venezuela e Trinidad e Tobago. A esmagadora maioria dos estudantes (97.4\%) veio de IES brasileiras. A Universidade do Porto recebeu 486 estudantes de universidades situadas entre as 100 primeiras do Ranking Iberoamericano SIR do Grupo SCIMAGO 2011, isto é, cerca de $57.2 \%$ dos estudantes latino-americanos. Desses, 180 estudantes, ou seja, cerca de $21 \%$ vieram de universidades situadas entre as dez primeiras posições do ranking.

6 As produções doentes e discentes forma acessadas através do acervo digital da biblioteca da Faculdade de Psicologia e Ciências da Educação da Universidade do Porto, FPCEUP. Disponível em: <https://sigarra. up.pt/up/pt>.

7 ALCE na Universidade do Porto foi, até ao ano letivo de 2006-07, uma licenciatura de quatro anos. No ano lectivo de 2007-08, operou-se a adequação ao Processo de Bolonha que prevê um $1^{\circ}$ ciclo de formação de três anos, que confere o grau de licenciado e um $2^{\circ}$ ciclo de formação, que confere o grau de mestre (VAZ, 2009).

\section{Referências}

ALMEIDA, L. et al. Democratização do acesso e do sucesso no ensino superior: uma reflexão a partir das realidades de Portugal e do Brasil. Revista Avaliação, Sorocaba, v. 17. n. 3, nov. 2012. Disponível em: <http://dx.doi.org/10.1590/S1414-40772012000300014>. Acesso em: out. 2016.

BARRETO, A. Tempo de incerteza. Lisboa: Relógio D’Agua, 2003.

CORTESÃO, L. Educação e exclusões: na tensão entre a cumplicidade e o embargo. In: CORTESÃO, L. (Org.). Porque uma outra educação possível: contributos para uma práxis transformadora. Porto: IPFP-CRPF, Legis, 2011.

CORTESÃO, L.; DALE, R.; MAGALHAES, A. (Org.). Educação em Portugal 40 anos após o 25 de abril de 1974. Revista Educação Sociedade e Culturas, Porto: CIIE/Edições Afrontamento, 2014. Disponível em: <http://www.fpce.up.pt/>. Acesso em: set. 2016.

CUNHA, M. I. A qualidade do ensino superior em tempos de democratização - a relação ensino e pesquisa. In: LEITE, et al. Políticas fundamentos e práticas do currículo. Porto: Porto Editora, 2011.

FONSECA, M.; ENCARNAÇÃO, S. A massificação do ensino superior em Portugal: efeitos espaciais na diversificação do sistema. In: COLÓQUIO IBÉRICO DE GEOGRAFIA, 13. Actas... Santiago de Compostela, 2012. Disponível em: <http://www.a3es.pt/sites/default/files/SpatialEffect_MFonseca_SEncarnacao.pdf>.Acesso em: out. 2016.

MAGALHÃES, A. M. Identidade do ensino superior: política, conhecimento e educação numa época de transição. Porto: Calouste Gulbekian, 2004. 
PRESTES, E. M. da T.; JEZINE, E.; SCOCUGLIA, A. C. Democratização do ensino superior brasileiro: o caso da Universidade Federal da Paraíba. Revista Lusófona de Educação, n. 21, p. 199-218, 2012. Disponível em: <http://revistas.ulusofona.pt/index.php/rleducacao/article/ view/3088/2328s>. Acesso em: out. 2016.

SANTOS, Boaventura de Souza. A globalização e as ciências sociais. São Paulo: Cortez, 2002.

STOER, S. R. Construindo a escola democrática através do "campo da recontextualização pedagógica”. Educação, Sociedade \& Cultura, Porto, n. 26, 2008. Disponível em: <http://www.fpce. up.pt/ciie/revistaesc/ESC1/stoer.pdf>. Acesso em: set. 2016.

STOER, S. R. Educação e globalização: entre regulação e emancipação. Revista Crítica de Ciências Sociais, n. 63, out. 2002. Disponível em: <http://www.ces.uc.pt/publicacoes/rccs/artigos/63/ RCCS63-033-045.Stephen\%20Stoer.pdf>. Acesso em: out. 2016.

STOER, S. R.; ARAUJO, H. C. Escola e aprendizagem para o trabalho num país da (semi)periferia europeia. Lisboa: Instituto de Inovação Educacional, 2000.

STOER, S. R.; CORTESÃO, L. Levantando a pedra: da pedagogia inter/ multicultural às políticas educativas numa época de transnacionalização. Porto: Afrontamento, 1999.

STOER, S. R.; CORTESÃO, L.; CORREIA, J. A. (Org.). Transnacionalização da educação: da crise da educação à 'educação' da crise. Porto: Afrontamento, 2001.

STOER, S. R.; CORTESÃO, L.; MAGALHÃES, A. M. A questão da impossibilidade racional de decidir e o despacho sobre os currículos alternativos. In: ESTRELA, A.; FERREIRA, J. (Org.). A decisão em educação. Lisboa: AFIRSE, 1998.

STOER, S. R. et al. Luiza Cortesão - uma homenagem. Porto: Instituto Paulo Freire de Portugal, 2004.

VAZ, H. Mediação em contexto de formação como reinvenção de novos ofícios- o caso dos estágios e da Licenciatura em Ciências da Educação na Universidade do Porto. Educação, Sociedade e Culturas, n. 29, p. 53-72, 2009. Disponível em: <http://www.fpce.up.pt/ciie>. Acesso em: set. 2016.

VEIGA-NETO, A.; LOPES, M. Inclusão, exclusão, in/exclusão. Revista Verve, São Paulo: PUC/SP, n. 20, 2011. Disponível em: <Revistas.pucsp.br/index.php/verve/article/download/14886/1111>. Acesso em: out. 2016. 